\title{
A 45-Year Perspective on Creativity Research: Comments on Glăveanu's Critique
}

\author{
Dean Keith Simonton \\ Department of Psychology, University of California, Davis, USA \\ E-mail address: dksimonton@ucdavis.edu
}

ARTICLE INFO

\section{Keywords:}

Bold conjectures

Conceptual definitions

Analytical units

Novel methodologies

Theoretical innovations

\section{Article history: \\ Received 18 September 2014 \\ Received in revised form 20 December 2014 \\ Accepted 21 December 2014}

ISSN: 2354-0036

DOI: 10.15290/ctra.2014.01.02.02
A B STRACT

In response to Glăveanu's critique of creativity research, this commentator argues that the highly productive research program that he has carried out over the past 45 years exemplifies almost all of the recommendations put forward in the critique. In particular, this extensive program has (a) asked bold, new, and surprising questions, (b) reflected on definitions rather than simply taking them for granted, (c) challenged traditional units of analysis, (d) looked for unique, interesting samples and developed new methods, and (e) built new theory rather than just cite it. The program's researcher might only be accused of failing to think practically about his conclusions. The comment closes by discussing the difficulties involved in pursuing such a rich research program as well as speculating on whether the field of creativity really should have numerous researchers engaged in such programs.

Although still only in my mid-60s, I consider myself now a "grand old man" of creativity research. I first began to familiarize myself with this research topic in the late 1960s, when I was an undergraduate. Although the 1970 thesis that resulted was not published until a decade later, some of its empirical predictions were tested in my 1973 "master's thesis" which was published in 1975. Since earning my doctoral degree in 1976 for a dissertation on the "social psychology of creativity," I have averaged about 10 publications per year - journal articles, chapters, books, encyclopedia entries, etc. - more than two thirds of which address some theoretical, empirical, or methodological topic concerning creativity. I am still publishing in top refereed journals today. All told, with the exception of one or two older colleagues (who I will refrain from naming), I probably can claim the longest long-term perspective on this research area than anybody currently active in the field.

Better yet, over the past four decades I have carried out a research program that exemplifies almost all of the half-dozen recommendations put forward in Glăveanu's critique. Let me check them off one by one. 
1. Ask bold, new, and surprising questions? Check! Rather than toot my own horn, I will just mention the honors that my research has received, including a best book award, several best article awards, and numerous career awards from different professional organizations (most notably, perhaps, the E. Paul Torrance Award from the National Association for Gifted Children which explicitly honored the creativity of my creativity research). I think it is not immodest to claim that I have empirically tested hypotheses that nobody ever thought were capable of testing - and continue to do so. For example, I recently published three articles (two empirical and one theoretical) that should completely change the debate about the relation between creativity and psychopathology (Damian \& Simonton, 2014; Simonton, 2014a, 2014b). Yes, the implications are that striking!

2. Reflect on definitions, do not simply take them for granted? I have devoted considerable effort to developing a three-criterion, quantitative and multiplicative definition of creativity that I believe has critical implications both theoretical and empirical (Simonton, 2012). For example, this definition has been extended to the critical distinction between little-c and Big-C creativity (Simonton, 2013c). Moreover, the definition provides the foundation not just for a major theory of creativity (Simonton, 2013a; see more below) but also for a novel approach to the question of free will (Simonton, 2013b).

3. Challenge traditional units of analysis? Again, check! Indeed, I know of no researcher living or deceased who has more varied the analytical units in his or her inquiries. Besides the individual creator (whether multiple case or single case), my work has extended from generational time-series analyses of whole civilizations and nations to the analysis of creative products, including films, poems, plays, artistic sketches, and musical themes.

4. Look for unique, interesting samples and develop new methods? Check again! Although I have published laboratory experiments using undergraduate participants, the overwhelming majority of my studies have scrutinized eminent creators and creative products representative of almost all of the world's great civilizations: ancient Greece and Rome, modern European, Islamic, Chinese, and Japanese. Not only do the samples represent domains of creativity as diverse as technology, science, philosophy, literature, music, art, and film, but I have focused on specialized subsamples to address certain questions, such as eminent African Americans. This historiometric work has incorporated cross -cultural studies and computerized content analyses, applied advanced statistical methods as varied as time-series analyses, structural equation models, both confirmatory and exploratory factor analyses, and cluster analysis. Moreover, I have elaborated my theoretical efforts using mathematical models and Monte Carlo simulations - speaking of which ...

5. Build theory, don't just cite it? Check once more! The efforts I have devoted to de- 
veloping a comprehensive and precise theory of creativity are well known. My fellow creativity researchers may or may not appreciate the idea that creativity can be best explained in terms of blind variation and selective retention, but at least I cannot be faulted for not working out the formal details and making the necessary connections with the cognitive, personality, developmental, and sociocultural aspects of the phenomenon. In fact, at present this work constitutes the only current theory of creativity that has generated and tested precise and unique empirical predictions. Nor was this any fly-by-night endeavor. These efforts began in the 1980s and continue today (e.g., Simonton, 2010).

6. Think practically about your conclusions? Oops, no. Nobody's perfect. I am not an educational, industrial/organizational, or clinical psychologist but rather a psychological scientist engaged in pure research. Given that most of my inquiries concentrate on Big-C creativity, it becomes less likely that such research will come up with useful suggestions about increasing little-c creativity. The best I can say for myself on this score is that a couple of my most mainstream studies have rather direct implications for increasing everyday creativity (e.g., Ritter et al., 2012). But I'm ok with being able check "yes!" on five out of six items on Glăveanu's wish list. Presumably, if many other creativity researchers score as high, even if on different items, our research area should no longer find itself in crisis. Furthermore, if I could do it, why not others too? Can I serve as a role model?

At this point, I must interject two reservations

First, pursuing such a research program is not easy. I have elsewhere recounted all of the obstacles that were thrown in my way, so I will not detail them here (Simonton, 2002). Worse yet, the current job market in academe - at least in countries following the North American model - has raised even more barriers. The current emphasis is on quantity over quality, with the subsequent necessity of publishing numerous short studies in high-prestige journals with incredibly rigorous rejection rates that require multiple revisions and resubmissions. Young job candidates often find themselves triaged from the get-go just because they have no publication yet in Psychological Science. In 1974 I managed to get a ladder-track position in the University of Arkansas without a single publication listed on my CV. Would that even be possible today?

Second, and perhaps most critically, we should be careful what we wish for. Does the field really need more researchers who generate their own methods, theories, definitions, and substantive questions? Wouldn't creativity research become even more scattered and incoherent? One advantage of everybody doing the same mainstream research is that everyone knows where the stream is going. But if many decide to start in different 
watersheds, they may find themselves boating different streams and eventually sailing on oceans far apart. To me, the only way to preserve unity in such diversity is to make sure that everybody is on the same page with respect to fundamentals - particularly core definitions and basic theory. Although I myself have offered recommendations with respect to both of these desiderata, I am under no illusions about whether that consensus will ever happen. Creativity researchers are too creative.

I hope to live sufficiently longer to learn whether these two reservations are justified.

\section{REFERENCES}

Damian, R.I. \& Simonton, D.K. (2014, August 4). Psychopathology, adversity, and creativity: Diversifying experiences in the development of eminent African-Americans. Journal of Personality and Social Psychology. Advance online publication. http://dx.doi.org/10.1037/pspi0000011

Ritter, S.M., Damian, R.I., Simonton, D.K., van Baaren, R.B., Strick, M., Derks, J., \& Dijksterhuis, A. (2012). Diversifying experiences enhance cognitive flexibility. Journal of Experimental Social Psychology, 48, 961-964.

Simonton, D.K. (2002). It's absolutely impossible? A longitudinal study of one psychologist's response to conventional naysayers. In R.J. Sternberg (Ed.), Psychologists defying the crowd: Stories of those who battled the establishment and won (pp. 238-254). Washington, DC: American Psychological Association.

Simonton, D.K. (2010). Creativity as blind-variation and selective-retention: Combinatorial models of exceptional creativity. Physics of Life Reviews, 7, 156-179.

Simonton, D.K. (2012). Taking the US Patent Office creativity criteria seriously: A quantitative three-criterion definition and its implications. Creativity Research Journal, 24, 97-106.

Simonton, D.K. (2013a). Creative thought as blind variation and selective retention: Why sightedness is inversely related to creativity. Journal of Theoretical and Philosophical Psychology, 33, 253-266.

Simonton, D.K. (2013b). Creative thoughts as acts of free will: A two-stage formal integration. Review of General Psychology, 17, 374-383.

Simonton, D.K (2013c). What is a creative idea? Little-c versus Big-C creativity. In J. Chan \& K. Thomas (Eds.), Handbook of research on creativity (pp. 69-83). Cheltenham Glos, UK: Edward Elgar.

Simonton, D.K. (2014a). The mad-genius paradox: Can creative people be more mentally healthy but highly creative people more mentally ill? Perspectives on Psychological Science, 9, 470-480. 
Simonton, D.K. (2014b). More method in the mad-genius controversy: A historiometric study of 204 historic creators. Psychology of Aesthetics, Creativity, and the Arts, 8, 53-61.

Corresponding author at: Dean Keith Simonton, Department of Psychology, University of California, Davis, Davis CA 95616 USA.

E-mail: dksimonton@ucdavis.edu 